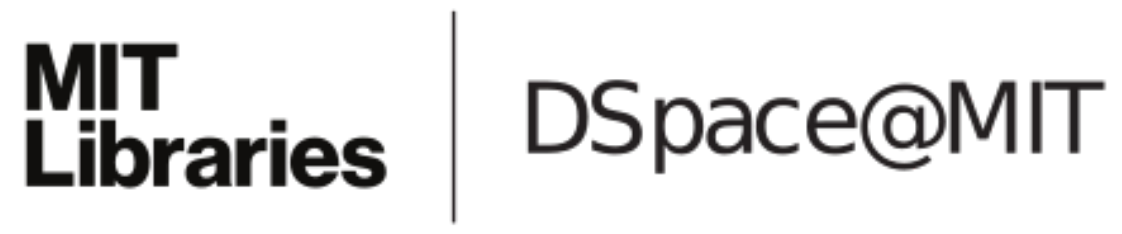

\author{
MIT Open Access Articles
}

The Hermeneutics of Recuperation: What a KinshipModel Approach to Children's Agency Could Do for Children's Literature and Childhood Studies

The MIT Faculty has made this article openly available. Please share how this access benefits you. Your story matters.

Citation: Gubar, Marah. "The Hermeneutics of Recuperation: What a Kinship-Model Approach to Children's Agency Could Do for Children's Literature and Childhood Studies." Jeunesse: Young People, Texts, Cultures 8, 1 (Summer 2016): 291-310 @ 2016 Project Muse

As Published: https://muse.jhu.edu/article/629409

Publisher: Johns Hopkins University Press

Persistent URL: http://hdl.handle.net/1721.1/112618

Version: Author's final manuscript: final author's manuscript post peer review, without publisher's formatting or copy editing

Terms of use: Creative Commons Attribution-Noncommercial-Share Alike 


\section{The Hermeneutics of Recuperation: What a Kinship-Model Approach to Children's Agency Could Do for Children's Literature and Childhood Studies}

- Marah Gubar

In the opening pages of her groundbreaking book Dependent States, cultural historian Karen Sánchez-Eppler clears a path for children's literature critics interested in challenging the notion that children function solely as passive recipients of culture. Without dismissing the key insights generated by Jacqueline Rose and other literary critics who treat childhood strictly "as a discourse among adults” (xvi), Sánchez-Eppler nevertheless announces her intention to regard children not merely as objects of socialization but also as "individuals inhabiting and negotiating" societal conceptions of what it means to be a child (xv). She thus sets out to analyze not just how American adults in the nineteenth century represented children but also how children represented themselves. To pay attention to children's diaries and other similar sources, she stresses carefully, "is not to pretend that children are fully independent actors, unhampered by the constraints of adult regulation and desire; but neither is it to see children as incapable of defining their own terms and grounds of power and meaning" (xxviii).

I agree with the idea that not just literary critics but everyone who participates in the interdisciplinary field of childhood studies should try to chart a middle course of this kind. That said, Sánchez-Eppler's account leaves open the question of exactly what kind of agency younger people have and how it compares to the sort generally belonging to older people. ${ }^{1}$ In what way do children "defin[e] their own terms and grounds of power and meaning”? Sánchez-Eppler frames her intervention in negative terms — children are neither independent nor incapable — and describes young people in the most neutral language possible, referring to them not as agents, or 
actors, or co-creators of culture but merely as "individuals" who start off their lives in a state of dependency. The bones of a theory about what it means to be a child are here, but there is no metaphorical meat on them. Or, to return to my earlier analogy, the middle ground SánchezEppler wants to inhabit remains mostly unmapped.

As a result, Sánchez-Eppler tends to tack back and forth between the two extremes she hopes to avoid. Keenly attuned (and rightly so) to the primacy and clout of grown-ups, she veers strongly toward the "incapable child" pole: the bulk of Dependent States focuses on "how structural and institutional power is enacted" on young people by their elders (xxiii), often resulting in "the abuse and death of individual children" (151). On the relatively rare occasions when she analyzes children's words and deeds, by contrast, Sánchez-Eppler swings back toward the "independent child" pole, as when she remarks on "the difficulties of disentangling the experiences of children from the discourses of childhood" (xxvii). This formulation suggests that somewhere - underneath all the grown-up interference - a pure signal pulses that originates solely from the child. Yet, since selfhood itself is shaped by language taught to us by others, shouldn't scholars who analyze children's writing resist the temptation to sort out which sentiments expressed in child-authored texts are truly attributable to young authors and which to the adults who surround them? After all, adult discourse is not a cloak that covers up some true, essential child; it is a constituting factor. ${ }^{2}$ But if we are barred from speculating about the degree to which adult pressure manifests itself in child-authored texts, then we cannot distinguish between, say, a passionate fan letter in which a child assures an actress she "adores" that "[n]obody knows I am writing to you, not even my mother" (qtd. in Bold 171) and the kind of rote note a schoolchild pens to an author that adheres to a teacher-approved formula. ${ }^{3}$ That seems problematic, too. 
Because of the complexity of this issue and the challenges of tracking down childgenerated documents from the distant past, it is tempting to dismiss the goal of locating children's agency as a "flawed intellectual project" (Alexander 123). That, I think, would be a mistake. But if childhood studies scholars want to continue talking about agency and analyzing children's writing, then perhaps we should back up a step and articulate in positive terms a theoretical model of what it means to be a child. Such a schema could help us to generate a more specific account of what we mean when we say that children have agency, which could then enable us to tweak or transform whatever discipline-specific methodologies we use to guide our analyses of children's words and actions. In this essay, I sketch out how this process might unfold under the aegis of what I call the "kinship model" of childhood. Let me stress from the start that this is not a schema I made up from scratch. Rather, it constitutes an attempt to develop the middle way toward which Sánchez-Eppler and others gesture - to name and flesh out a model of childhood that is already implicit in their work. For, despite the passage that I just quoted and queried, many other moments in Dependent States make it clear that Sánchez-Eppler does not actually believe in the existence of an essential self unmediated by language and culture. She emphasizes - and I agree - that any account of what it means to be a child must acknowledge that human beings begin life in a state of dependency, immersed in discourses not of our own making that ineluctably affect how we conceive of ourselves and the world around us (xxv). If we as scholars want to claim that children have agency, then, we must concede that the kind of agency they have is not synonymous with autonomy.

Helpful as this insight is, however, it is still a negative formation: “Don't equate children's agency with autonomy." Why is it so hard to generate positive theories about children's agency? Partly because, as literary critic Anna Mae Duane points out, "Childhood 
studies, a field designed to dismantle inaccurate and often destructive definitions of childhood, has yet to come up with a consensus on what we mean when we say 'child' in the first place" (15). Even philosopher Gareth B. Matthews - a standout in his field because he pays sustained attention to children - refuses to philosophize on this subject, declaring that "no one today is in a position to present an altogether adequate theory of childhood that would command the respect of developmental psychologists, anthropologists, linguists, . . . educational theorists,” and so on (25). Speaking on a plenary panel on "The Futures of Childhood Studies" at the University of Notre Dame in December 2014, sociologist Daniel Cook characterized this collective reluctance to theorize not as a problem but as a positive benefit, a sign of the sensitivity of scholars in our field to the dangers of generalization. So, before we even begin trying to answer the question "What is a child?," some preliminary queries demand our attention. Why have so many of us working in childhood studies been content to dispose, not propose? What legitimate concerns have held us back from hazarding positive theories about what it means to be a child?

One reason why we have remained mostly silent on this subject, I think, is that we are justifiably uncomfortable with the idea that all children share essential characteristics that differentiate them decisively from adults. The categories "child" and adult" carve up the human community neatly into two separate and unequal classes of people. Yet most of us likely would agree that growth is actually a messy continuum, an ongoing process that involves losses as well as gains. Our capacities for reflectiveness, rationality, self-control—or whatever qualities we deem necessary before agents should be allowed to make their own choices free from parental (or in loco parentis) supervision - tend to develop gradually over time. But these capacities do not always and inevitably correlate with age: some twelve-year-olds may have them; some fiftyyear-olds may not. Generalizing about what powers and abilities children do (or do not) have is 
problematic because children, like adults, are a heterogeneous bunch. To borrow and reapply an observation made by queer theorist Eve Kosofsky Sedgwick: "People are different from each other. It is astonishing how few respectable conceptual tools we have for dealing with this selfevident fact" (22).

Another excellent reason for adult reticence regarding the nature of childhood is the phenomenon that philosopher Ian Hacking dubs "the looping effect of human kinds" (59). Hacking points out that, when human beings are classified as belonging to a group that is considered to have (or lack) particular qualities, it can change the way they are treated as well as "the ways in which individuals experience themselves - and may even lead people to evolve their feelings and behavior in part because they are so classified" (104). Children as a group, Hacking observes, are subject to this looping effect:

Children are conscious, self-conscious, very aware of their social environment, less articulate than many adults, perhaps, but, in a word, aware. People, including children, are agents, they act, as the philosophers say, under descriptions. The courses of action they choose, and indeed their ways of being, are by no means independent of the available descriptions under which they may act. (103)

Hacking notes that targets of knowledge in the social sciences_-"children," "schizophrenics," "women refugees"- are not fixed and immutable; they are instead "on the move" because the way in which different cultures in different times conceptualize such groups affects how their members conceive of themselves and interact with the world (108). But Hacking also stresses that this process is not unidirectional: the way that members of a group act can modify and 
transform the discourse, which is why he refers to such groups as "interactive kinds" (103). Cultural historian Robin Bernstein makes a similar point when she encourages childhood studies scholars to acknowledge the "simultaneity and mutual constitution of children and childhood" (22). Adult discourse about what childhood is (or should be) shapes the lives and experiences of individual children, but that discourse is also shaped by the comportment, doings, and utterances of young people. Shifts in how adults talk about children can change how children behave, but how children behave can also shift how adults talk about them. Hacking's looping analogy indicates his belief that this process resembles a roundabout more than a one-way street.

Or, if you will allow me to change metaphors midstream, we might say that both Hacking and Bernstein conceive of children as actors who are simultaneously scripted and scripting. This way of thinking about what it means to be a child has significant benefits. It accords children agency without denying that they are shaped by a classification that pre-exists their arrival in the world, one that has spawned a matrix of adult-controlled discourses and practices that affect how young people perceive themselves and their relationship to the world they inhabit. There is something powerfully egalitarian and respectful about Bernstein's vision of children as "virtuoso performers" of childhood (28) and Hacking's characterization of them as fully agential, just another group under the big tent "People" (103).

Yet while these formulations are very appealing, we may feel a nagging anxiety that, in general, children are more scripted and less scripting than grown-ups. At a 2012 symposium on "Performing Childhood Studies" at Texas A\&M University, after Bernstein and I had both articulated visions of the simultaneously scripted-and-scripting child, literary critic Lucia Hodgson objected, “Couldn't you say the very same thing about adults?” Her concern has coloured my thinking on this subject ever since. Children, like adults, are different from one 
another. Nevertheless, human beings choose to categorize some people as children and others, not. Why? Part of the reason, I think, is that we worry that children's capacity to "modify and transform the discourse" about the category "child" is generally more limited than adults' capacity to interact with the groups (or kinds) to which they belong.

Theorizing about what exactly the child-adult distinction is supposed to pick out, philosopher Tamar Schapiro observes, "To treat someone like a child, is, roughly, to treat her as if her life is not quite her own to lead and as if her choices are not quite her own to make" (715). I find this formulation very helpful. Rather than presuming that adult paternalism toward children is ipso facto oppressive, Schapiro and other analytic philosophers invite us to consider when and why it is justified. One of Hacking's reasons for coining the term "interactive kind" is his conviction that "[w]e need to make room ... for both the [social] constructionist and the biologist" when we study some of these groups (109). In the case of children, the biologist would likely point out that human beings begin life in a state of relative helplessness and inarticulateness. We are not born with the ability to take care of ourselves, speak on our own behalf, and make decisions about how to manage our own lives. Our survival and wellbeing depend on the mercy of caregivers who have more competencies and powers than we do.

Attuned to this power asymmetry, literary critics such as Rose and Perry Nodelman and sociologists such as Allison James have compared the adult-child relationship to colonization, urging us to carry over the insights gained from researching, theorizing, and writing about "the other"-in anthropology as well as in literary and cultural studies — to scholarship focused on children (Nodelman, "Other" 29; James 262). Useful as the metaphor of colonization has been, however, it tends to obscure the key problem we must grapple with when theorizing children's agency: whereas British imperialists (for example) were wrong to claim that Indians and 
Africans were too immature to take care of themselves, most of us would likely agree that, in the case of very young children, some form of paternalism is not only justified but ethically required. Comparing children's status to that of colonized subjects, women under patriarchy, or queer people in a heteronormative culture has been (and continues to be) enlightening. But none of these analogies acknowledges that children enter the world in a state of dependency that makes it not merely justifiable but ethically incumbent upon their caregivers to treat them in ways that would seem offensively authoritarian if applied to other historically marginalized groups. If children are "other," then, they are another kind of other.

But do we really want to embrace a vision of what it means to be a child that insists above all on the child's alterity? Maybe not, because it seems risky to adhere to what I call the "difference model" of childhood ("Risky" 451). The history of how human beings have treated groups marked out as alien "others" suggests that this way of thinking too easily produces prejudice and injustice, condescension and dehumanization. Perhaps this is because human beings struggle to regard difference with complete neutrality; we tend either to valorize or to disapprove of it. Indeed, cultural historians such as James R. Kincaid and Marina Warner have shown us that, when adults conceive of children as a separate species, we often either idealize or demonize them—or both, since embracing a romanticized vision of children as "little angels" has often caused adults to regard young people who fail to live up to this punishingly high standard as "little monsters." Moreover, even if we vow to remain neutral about the nature of the child's alleged otherness, we nevertheless are liable to devalue it because we inhabit a profoundly "aetonormative" culture, meaning that—however much we profess to adore young people—we generally regard adulthood as the normal and preferred state of being. ${ }^{4}$ The synonyms that the 
word "childish" brings to mind—silly, inept—attest to this point, as does the glaring absence of institutional archives that collect and preserve children’s writing (Sánchez-Eppler xvii).

Yet any justification for paternalism would seem to rest on the widely shared intuition that children's agency is somehow dissimilar: that "the words and deeds of children have a different status or significance than the words and deeds of adults," making it acceptable to treat them as if their lives are "not quite [their] own to lead" (Schapiro 715-16). So it is worth thinking about what a difference-model approach to children's agency would look like, if only to understand why we should rule it out and to help ourselves imagine better alternatives. To that end, we can use the difference model to generate the following theory: "Adults have one kind of agency; children have a different kind." This purposely generic account clarifies matters by helping us to see that all theories of children's agency that adhere to this basic format will fail to address the legitimate concerns outlined above regarding the act of theorizing about childhood. Why? First, because such theories draw too sharp a line between children and adults, thereby refusing to acknowledge human heterogeneity. Ironically, difference-model theories of children's agency are too inattentive to difference, in the sense that they make no allowance for the possibility that some children might exercise the same sort of agency as some adults, or even outperform grown-ups as thinkers, doers, and writers.

Second, the inflexibility of this stance makes us more liable to treat children in ways that set into motion potentially disabling looping effects. If we adults do not conceive of young people as possible exercisers of the same sort of agency that we possess, then we are less likely to treat them in ways that help them to develop the competencies associated with that sort of agency. To understand why this is so, imagine a parent committed to the difference-model view that adults are rational beings and children are emotional or instinctual ones. When a decision- 
making opportunity comes up, that parent is unlikely to share her own reasoning process with her child or to invite the child to participate in the weighing of pros and cons. After all, she believes that children, unlike adults, are wholly unamenable to rational persuasion. So she would have to be irrational herself to try to teach her child how to reason. As this counterfactual scenario suggests, conceiving of children as fundamentally different from adults can function as a selffulfilling prophecy: adult assumptions about children's alterity may lead older people to deprive younger ones of opportunities to exercise, learn about, or refine skills associated with the adult domain (in this case, rational deliberation, but this point holds true for whatever competencies we consider pertinent to the process of making one's own life choices).

Having recognized that no difference-model theory of children's agency is likely to assuage our legitimate concerns, we can now turn our attention to other kinds of accounts, like this one: "Adults have agency; children have less of it." This is the type of theory we get if we adhere to what I call the "deficit model" of childhood, meaning that we take deficiency as our primary metaphor when we think about what it means to be a child. The moment we make this model explicit, however, we can see that any theory of agency that can be translated into these terms will likewise fail to address the legitimate concerns outlined above. To presume that children always have less agency than adults is to ignore Sedgwick's point that "[p]eople are different from each other." Even a quite young child might have considerably more agency than an adult, whether because of the vagaries of the developmental process (for example, neurodiversity) or because of social conditions that grant a particular kind or class of children more decision-making power than adults around them who belong to a still more disenfranchised group. 
Moreover, the existence of the looping effect means that, even if children of a certain age are generally deficient to adults in terms of how much agency they have, we should nevertheless resist the impulse to characterize their agency as partial and inferior because this description risks exacerbating, perpetuating, or even bringing into being the condition it claims only to describe. Social-science research on what is known as the "teacher expectancy effect" provides some support for this point, since it suggests that viewing children as deficient—as unable to grasp certain concepts or skills - can help produce the very incapacities we claim merely to describe. $^{5}$

We can use the deficit model to generate a negative prohibition that represents the beginning of a plan for how to analyze children's letters like the ones I mentioned near the start of this essay. Children's letters should not be automatically regarded as intrinsically less reliable than adult letters — not because age-related limitations and constraints never affect children's writing in ways that we might need to acknowledge, but because it is essentialist, disrespectful, and potentially disabling to young people to presume that they always do.

As should be evident by now, these models are meant to function more like tools than mirrors, and one thing that they enable childhood studies scholars to do is to clarify why we have generally chosen to dispose rather than propose, to dismantle problematic accounts of what it means to be a child rather than build better ones. When we try to theorize about childhood, we face a vexing double bind. On the one hand, it seems important to acknowledge the child's original dependency and the limitations that attend routinely the state of being a biologically immature human being. After all, these limitations are what justify adults in treating children as children (not allowing four-year-olds to drive cars and sign contracts, for example). On the other hand, because adult discourse about childhood can function easily as a self-fulfilling prophecy, 
the moment we try to describe such limitations, we risk setting into motion a disabling looping effect whereby we perpetuate, contribute to, or even produce them. Childhood studies scholars have refrained from theorizing about what it means to be a child because we sense that it would be a mistake to take either deficiency or alterity as our governing metaphor when we hypothesize about this subject and because we worry that any theorizing will reify the category "child" by presuming a binary opposition between child and adult that is premised on biological essentialism and that ignores the fact that development is a messy and variable process affected by cultural and social—as well as by biological and physiological—factors.

But rather than allow such concerns to stop us from theorizing, suppose we try to come up with positive models of what it means to be a child that take these worries into account. Pace Matthews, I believe we can lay out an "adequate theory of childhood" that could appeal to scholars working on childhood in various disciplines - because I see such a model as already implicit in the work of a wide range of people, including philosophers such as Matthews and Hacking, cultural historians such as Sánchez-Eppler and Bernstein, and sociologists such as Alan Prout who have recently begun to move away from "bio-social dualism" and toward conceiving of childhood as a both-and phenomenon (Lee and Motzkau 8). I call it the "kinship model" of childhood. Adhering to this model means maintaining that children and adults are fundamentally akin to one another, even if certain differences or deficiencies routinely attend certain parts of the aging process.

The concept of kinship encapsulates this delicate balancing act and, in so doing, helps us to perform it. Unlike models linked to analogies like "the child is an alien other" or "the child is a universal novice," a schema built around the "child is kin" metaphor prompts us to regard all human beings, regardless of age, as full subjects under the big tent "People." Even as the concept 
of kinship highlights likeness and relatedness, however, it also makes room for difference and variation. Consider, for example, your own kinspeople: however closely related you are to other members of your family, you are unlike them, too. By its very existence as a mode of discourse about children, the kinship model assumes that young people have enough commonalities with each other — and differences from adults — to justify some form of adult paternalism and our continued use of the category "child." Yet it also aims to function as the kind of conceptual tool that Sedgwick calls for by making room for the fact that children — like adults, women, and indeed all human groups - are such a diverse population that we can rarely (if ever) indulge in confident generalizations about them. To counteract the fact that having any model of what it means to be a child risks reifying the category and setting into motion disabling looping effects, adherents to the kinship model insist first and foremost on how alike younger and older people are. Only after emphasizing this elemental similarity do they acknowledge —using obstinately tentative language - the possibility of age-related differences and deficiencies.

Because we inhabit an aetonormative culture, stressing the similarities that link children and adults often involves a perspectival flip: instead of presuming that adults represent the norm and then investigating how children deviate from that norm, kinship-model adherents test out what happens if we regard the position that children generally inhabit as standard or shared. Consider agency, for example. Rather than assume that adults are full-fledged autonomous agents and then attempt to discern how children fail to live up to that standard, a kinship-model adherent is more likely to note that all human beings begin life in a compromised position, a state of dependency in which key decisions about who we are and how we live our lives are being made for us, affecting how we conceive of ourselves and the world around us. ${ }^{6}$ Even if we pick up many skills and abilities as we age that enable us to function more independently, we never 
fully outgrow that originally compromised state. So, the issue of how much agency a person has is always, at some level, a messy one.

A kinship-model theory of agency might therefore sound something like this: "Children, like adults, have agency, even if aspects of the aging process are likely to limit the form or degree of agency that they have." In other words, having the kinship model enables childhood studies scholars to justify an impulse that was integral to the foundation of our field in its modern form: namely, the belief — shared by anthropologists, cultural historians, sociologists, and literary critics - that scholars ought to attribute agency to children as social actors. Pace Duane, childhood studies did not emerge solely because researchers wanted to dismantle bad accounts of childhood but also because they wanted to build better ones, often by treating children themselves not as "passive objects" but rather as valued "informants" whose voices had too often been "muted" (Hardman 87, 85). What the history of our field suggests, I think, is that adults who maintain that children have agency are more likely than ones who don't to pay close attention to the words and deeds of young people, to seek out material traces of children's agency that might otherwise go uncollected, unanalyzed, missing.

Speaking as someone who has spent many hours combing through archives, I can say that if I did not believe that a passionately worded, avowedly self-motivated fan letter was more reflective of the writer's thoughts and feelings than a classroom-generated, cookie-cutter memo, then I would not work so hard to dig up documents that resemble the former more than the latter. When I look back at my analyses of child-generated fan letters and reviews of Peter Pan, I notice that I adopted a kinship-model approach avant la lettre by assuming that I had the power to discriminate between more and less revealing documents on the basis of textual and contextual clues, much as I do when I analyze adult-authored texts. At the same time, however, I repeatedly 
acknowledged that "any discussion of the preferences and practices of child playgoers raises serious epistemological problems," including the fact that children very often (though not always) have less control over their theatre-related activities than adults ("Peter Pan" 478). Rather than denying this complicating factor, I proposed, we can try to mitigate it by "collat[ing] different kinds of corroborative evidence, even as we acknowledge that our conclusions can only ever be tentative, since our knowledge is inevitably fractional, incomplete" (478). Instead of using children's written reactions to plays such as Peter Pan to generalize in confident terms about what young people thought, we acknowledge that [d]ifferent children undoubtedly reacted in different ways to different productions, and most left no record at all of their responses. For others, writing long after the fact in memoirs, nostalgia may have distorted their recollections of youthful playgoing. Yet these problems should not arrest our inquiry; after all, they affect all attempts to trace audience reactions to productions from the distant past...For this reason, a cautious humility should govern the kinds of claims we make about adult spectators, as well. ("Peter Pan" 479)

There it is: the perspectival flip in action. But my point is not that I am the first or only childhood studies scholar to adopt this type of approach. Quite the contrary: I advocate for the kinship model because I think it encapsulates the best practices of many of us, including historian Mary Jo Maynes (118), sociologists Priscilla Alderson and Tamaki Yoshida (77), and literary critics Sánchez-Eppler (xxv) and Beverly Lyon Clark $(1-7,13)$.

Even as the kinship model helps childhood studies scholars to make sense of our past, it gently nudges us to embrace an even more interdisciplinary future, since the kind of theories that it generates stake out some space for scholars whose disciplines equip them to hypothesize about 
age-linked limitations and differences, such as biologists and developmental psychologists. Speaking of intellectual equipment, you may be wondering what qualifies a literary critic like me to dabble in the philosophy of childhood. My rationale is that my field has trained me to isolate particular modes of discourse and to trace how they affect what people write, say, and do. Because of the existence of the looping effect, it genuinely matters what kind of language we use when we talk about children, particularly if we are credited with having any kind of expertise on this subject. History suggests that, when human beings think about what it means to be a child, we do so by means of analogy, and also that certain types of analogies are more potentially disabling than others. Articulating an amendable list of models of what it means to be a child can help us to mind our metaphors as we think, talk, and write about children.

If Sánchez-Eppler had been working with these models in Dependent States, for example, she might not have chosen to describe children as "partial subject[s]" (xxvii), a phrase fully in line with the deficit model since it implies that adults have things like subjectivity, agency, and voice, whereas children have less of them. When even the most cautious and astute scholars of childhood find it hard to steer clear of potentially disabling language, this difficulty attests, I think, to the value of having a positive model, one that is easier to adhere to precisely because it relies on a metaphorically meaty concept such as kinship. Or consider the case of developmental psychologist Alison Gopnik, who has lucidly observed that "[o]ften, progress in science begins with finding the right analogy" ("Scientist" 485). Gopnik has spent her career promoting the kinship-model theory that babies are less like mindless vegetables than fellow "scientists in the crib." Yet she and her collaborators sometimes drift back to using deeply dehumanizing language to describe infants, describing them as "completely useless" (Gopnik, Philosophical 71) or comparing them to aliens from another planet (Gopnik, Meltzoff, and Kuhl 2). Being familiar 
with the deficit, difference, and kinship models could help Gopnik and other scientists not only to weed out such inconsistencies but also to understand why it matters which metaphors we use.

The time has come to make a humbling admission. I began this piece by hinting that I would supply a more specific account of what childhood studies scholars might mean when we say that children have agency. Yet, as you may have noticed, the statement about children's agency generated by the kinship model is just as generic as the ones produced by other models. Like Sánchez-Eppler, in other words, I have not managed to spell out exactly what I mean when I say that children have agency; all I have done is to explain the benefits of a particular type of account that, I claim, constitutes an improvement over two other kinds of accounts.

Bear with me, though, because I have several excellent excuses for this failure, the first of which applies both to me and to Sánchez-Eppler. Like the query "What is a child?," "What is agency?" is a philosophical question, meaning that there is not yet any accepted methodology for how to go about answering it. Prout, for example, relies on Actor-Network Theory, while Bernstein makes use of postmodernist accounts of the performative nature of identity. Some analytic philosophers, following in the footsteps of G. E. M. Anscombe, define agency in terms of knowing what we are doing and why, while others such as Michael Bratman and Nomy Arpaly object that such accounts over-intellectualize agency.

My point is that there is no shame in struggling toward a solution to this problem rather than solving it completely. The fact that it is very difficult to define what agency is and that childhood studies scholars are unlikely to come to a consensus on this subject any time soon (if ever) does not mean that we should characterize the project of locating children's agency as "flawed" (Alexander 123). Humanists and social scientists have grown so comfortable with the hyper-skeptical intellectual style that literary critic Rita Felski calls "critique" that, when we do 
not know how to define something, our first impulse is, often, to discard, dismantle, or problematize it. Perhaps that is why sociologist David Oswell opens his thoughtful and informative book The Agency of Children by reassuring readers that he will provide "not any kind of theory of children's agency" but rather "ope[n] up the problem of children's agency for further investigation" (8). I am all for further investigation, but I-along with many scientists and analytic philosophers - think that formulating positive hypotheses is a key part of the problem-solving process.

So, until another childhood studies scholar proposes a better option, I suggest that we take a kinship-model approach when we theorize about children's agency, thereby affirming, extending, and developing our field's long-standing commitment to respecting children's status as agents. Such a stance moves us away from the "hermeneutics of suspicion" that Felski describes so brilliantly and toward what we might call the hermeneutics of recuperation, a rigorous yet generous style of thinking that allows us to appreciate as well as criticize, believe as well as doubt, build and tinker as well as dismantle and deconstruct. That brings me to my second excuse for failing to offer my own account of children's agency: namely, that I like the ones supplied by Hacking, Bernstein, Prout, and others. Adopting the kinship model does not require us to jettison the "child is actor" analogy they favor. On the contrary, it helps us to understand why it so appealing: precisely because it can be applied to agents of all ages without foreclosing the possibility that age-related differences and deficiencies might exist that ought to be acknowledged. Categorizing this way of thinking as a kinship-model approach does not commit us to affirming children's competencies (such as the ability to resist social pressures) so much as it indicates our desire to find the least prescriptive way of admitting that various vulnerabilities, limitations, and constraints might attend particular parts of the aging process. 
My third and final excuse for not supplying a definition of agency is that my real goal here has been to answer the first question, not the second one: to lay out a new methodology for how to think about the question "What is a child?" My method, which was inspired by the work of philosophers such as Matthews, Schapiro, and David Archard, consists of articulating an amendable list of models of what it means to be a child that can be used by a wide variety of people. Viewed in this light, the fact that such models can generate content-neutral theories is a feature, not a bug, since such theories can then be used in different ways by scholars working in different disciplines. A recurring concern in childhood studies scholarship is the lack of communication and collaboration between researchers in the humanities, the social sciences, and the natural sciences. If enough of us agree to use them, then having models could help us to talk with (rather than past) one another. To put this point another way, a philosophy of childhood informed by work that has already been done in childhood studies could function as a bridge between disciplines, providing us with a shared language that could help our field become as interdisciplinary as it aspires to be. Here, too, a more recuperative, tentative, and inclusive style of discourse could help us. If we want developmental psychologists to pay more attention to what the rest of us are saying, for instance, then we probably should not describe their discipline as "hegemonic" even as we voice the appeal (Thorne 150).

If any field could stand to put a little more distance between itself and the hermeneutics of suspicion, that field is children's literature studies, as literary critic Richard Flynn has observed ("Culture" 65). Felski does not mention my disciplinary home in her account of how a "kudzu-like proliferation of a hypercritical style of analysis . . . crowded out alternative forms of intellectual life" during the last quarter of the twentieth century (10). But her description perfectly matches my memory of the late 1990s and the 2000s, when I was struggling to write 
and publish work that did not conform to the vision of how to think about children's literature that Rose outlined in her 1984 manifesto The Case of Peter Pan, or the Impossibility of Children's Fiction. What made Dependent States so groundbreaking in 2005 was that SánchezEppler treats children not only as the objects of adult efforts to socialize them but also as "participants in the making of social meaning" (xv). This both-and approach constitutes an implicit challenge to Rose's radically negative declaration that "[t]here is no child behind the category 'children's fiction,' other than the one which the category itself sets into place" (10). According to Rose, actual children are involved in children's literature to such a minimal degree that it is probably best for literary critics to avoid all mention of them. After all, their input and influence over the production of children's literature is negligible, and evidence regarding how they have responded to particular texts is not merely scanty but "more or less impossible to gauge" even when we find it (Rose 9).

Perhaps there is no need to criticize or to reject Rose's paradigm, given that SánchezEppler and many other scholars have managed to do their pioneering work without elaborating an alternative to it. ${ }^{7}$ Yet it bothers me that children's literature critics are still working under the aegis of a theoretical framework that is such a poor fit for the innovative and often interdisciplinary work that so many of us are currently doing. ${ }^{8}$ Partly for this reason, I am in favour of articulating a positive alternative to Rose's approach that situates children's literature studies as one of the disciplines that together make up the broader field of childhood studies. If other children's literature critics share my interest in this possibility, then we can use the philosophical schema that I have sketched out here to help our theory catch up with our practice. We can acknowledge that adults wield immense influence over children's culture without going so far as to define children's literature as "an adult practice” (Nodelman, Hidden 4). That Rose- 
inspired approach is fully in keeping with the difference model, since it draws a strict line of division between adults (who participate in this cultural phenomenon) and children (who do not).

I propose that we instead start from the kinship-model premise that younger people, like older ones, are involved in various and complex ways with children's literature. Once we acknowledge this underlying likeness, then we can focus on noticing differences, such as the fact that most—although not all—children's literature is written by adults. For this reason, the important work of analyzing how adult-authored children's texts disseminate ideologies that might prove harmful to minors should (of course) continue. But a new paradigm built on the kinship model of childhood would make room for other kinds of work, too, including the archiving and analysis of youth-generated online writing of the kind that cultural historian Sara L. Schwebel mentions in her contribution to this forum. The issue of how to curate and preserve such materials, she observes, requires our immediate attention. I agree and would add that interpreting such materials may well require us to elaborate new methodologies. The question is, should such work proceed under the aegis of a paradigm that characterizes youth involvement in youth culture as negligible, largely inaccessible, and virtually impossible to analyze? Or should we work together to create a more capacious critical framework that affirms our respect for children's agency as participants in culture and helps us to develop theoretically well-grounded methodologies for analyzing their involvement? I am in favour of the second option, although I am also open to "the permanent possibility of someone's having a better idea" (Rorty 349).

\section{Acknowledgements}

Many thanks to Richard Flynn, both for his probing work on the subject of children's agency and for organizing the panel that gave rise to this forum. Thanks also to Clementine Beauvais, Tyler 
Bickford, Daniel Cook, Corey Creekmur, Lucia Hodgson, Mary Celeste Kearney, Karen Lury, Mavis Reimer, Kieran Setiya, Victoria Ford Smith, Courtney Weikle-Mills, and Pamela Robertson Wojcik, all of whom offered perceptive feedback on various versions of this piece.

\section{Notes}

${ }^{1}$ Sánchez-Eppler's reticence on this point is representative, not idiosyncratic. Sociologist Alan Prout has observed that the question of what it means to be an agent often goes unaddressed within the field of childhood studies (64-5). The editors of the 2016 volume Reconceptualising Agency and Childhood likewise stress this point (Esser et al, 1, 7), even as they and their contributors help to remedy it.

${ }^{2}$ My thinking on this point has been influenced by the work of Anna Redcay and Peter E. Cumming.

${ }^{3}$ The first letter was written by a twelve-year-old girl named Lita to actress Hilda Trevelyan, who originated the role of Wendy in Peter Pan. Sara L. Schwebel introduces examples of the second type in her contribution to this forum.

${ }^{4}$ This useful term was coined and defined by Maria Nikolajeva (8).

${ }^{5}$ This phenomenon is also known as the "Pygmalion effect," because Robert Rosenthal and Lenore Jacobson introduced it in their study Pygmalion in the Classroom. For a review of some of the resulting research in this area, see Good and Nichols.

${ }^{6}$ This aspect of the kinship model was inspired by Sánchez-Eppler's observation in Dependent States that paying attention to childhood forces us 
to examine what it might mean to claim voice, agency, or rights for a figure who is not, cannot, and indeed should not be fully autonomous. Children's dependent state embodies a mode of identity, a relation to family, institution, or nation, that may indeed offer a more accurate and productive model for social interaction than the ideal autonomous individual of liberalism's rights discourse ever has. (xxv)

Duane elaborates and expands on this view and, in so doing, anticipates many key tenets of the kinship model (5-7).

${ }^{7}$ Literary critic Laurie Langbauer seems to adopt this position when she aligns herself appreciatively with scholars of juvenilia who devote their time "primarily to uncovering and conserving [children's] writing" rather than hatching theories to guide our analysis of such texts (890). To my mind, though, the question is not "Should we generate theories?" but rather "Are we willing to own up to the implicit theories that are already informing our practices?"

${ }^{8} \mathrm{I}$ am thinking here about the exciting work in progress of emerging scholars such as Victoria Ford Smith, Tyler Bickford, Meredith A. Bak, and Julian Gill-Peterson, as well as older scholarship by many critics, some of whom I have listed elsewhere ("Risky" 455). Richard Flynn anticipated this shift in 2011 ("Culture" 66).

\section{Works Cited}

Alderson, Priscilla, and Tamaki Yoshida. “Meanings of Children's Agency: When and Where Does Agency Begin and End?" Reconceptualising Agency and Childhood, ed. Esser et al. $75-88$.

Alexander, Kristine. "Agency and Emotion Work." Jeunesse 7.2 (2015): 120-28. Print. Anscombe, G. E. M. Intention. $2^{\text {nd }}$. Ed. Oxford: Blackwell, 1963. Print. 
Archard, David. Children: Rights and Childhood. New York: Routledge, 1993. Print.

Arpaly, Nomy. Unprincipled Virtue: An Inquiry into Moral Agency. New York: Oxford UP, 2003. Print.

Bernstein, Robin. Racial Innocence: Performing American Childhood from Slavery to Civil Rights. Cambridge: Harvard UP, 2011. Print.

Bold, Valentina. “'A Love that is Real': Children's Responses to Wendy.” Gateway to the Modern: Resituating J. M. Barrie. Ed. Valentina Bold and Andrew Nash. Glasgow: Association for Scottish Literary Studies, 2014. 167-185. Print.

Bratman, Michael. Intention, Plans, and Practical Reason. Cambridge: Harvard UP, 1987. Print.

Clark, Beverly Lyon. The Afterlife of Little Women. Baltimore: Johns Hopkins UP, 2014. Print.

Cook, Daniel. "Disrupting Play." Fun with Dick and Jane: Gender and Childhood, U of Notre Dame. 4 Dec. 2014. Address.

Cumming, Peter E. "What Children's Writing? Read by Whom, How, and to What Ends?" CCL/LCJ 34.1 (2008): 106-15. Print.

Duane, Anna Mae, ed. The Children's Table: Childhood Studies and the Humanities. Athens: U of Georgia P, 2013. Print.

Esser, Florian, Meike S. Baader, Tanja Betz, and Beatrice Hungerland, eds. Reconceptualising Agency and Childhood: New Perspectives in Childhood Studies. New York: Routledge, 2016.

Felski, Rita. The Limits of Critique. Chicago: U of Chicago P, 2015. Print.

Flynn, Richard. "Culture." Keywords for Children's Literature. Ed. Philip Nel and Lissa Paul. New York: New York UP, 2011. 62-66. Print. 
Good, Thomas L., and Sharon L. Nichols. "Expectancy Effects in the Classroom: A Special Focus on Improving the Reading Performance of Minority Students in First-Grade Classrooms.” Educational Psychologist 36.2 (2001): 113-26. Print.

Gopnik, Alison. “The Scientist as Child.” Philosophy of Science 63.4 (1996): 485-514. Print.

Gopnik, Alison. The Philosophical Baby. New York: Picador, 2009. Print.

Gopnik, Alison, Andrew N. Meltzoff, and Patricia K. Kuhl. The Scientist in the Crib. New York: HarperCollins, 1999. Print.

Gubar, Marah. “Peter Pan as Children's Theatre: The Issue of Audience.” The Oxford Handbook of Children's Literature. Ed. Julia Mickenberg and Lynn Vallone. New York: Oxford University Press, 2011. 475-96. Print.

---. "Risky Business: Talking about Children in Children's Literature Criticism.” Children's Literature Association Quarterly 38.4 (2013): 450-57. Print.

Hacking, Ian. The Social Construction of What? Cambridge: Harvard UP, 1999. Print.

Hardman, Charlotte. “Can There Be an Anthropology of Children?” Journal of the Anthropological Society of Oxford 4.2 (1973): 85-99. Print.

James, Allison. “Giving Voice to Children's Voices: Practices and Problems, Pitfalls and Potentials." American Anthropology 109.2 (2007): 261-72. Print.

Kincaid, James R. Child-Loving: The Erotic Child and Victorian Literature. New York: Routledge, 1994. Print.

Langbauer, Laurie. "Prolepsis and the Tradition of Juvenile Writing: Henry Kirke White and Robert Southey.” PMLA 128.4 (2013): 888-905. Print.

Lee, Nick, and Johanna Motzkau. "Navigating the Bio-politics of Childhood." Childhood 18.1 (2011): 7-19. Scholars Portal. Web. 7 June 2016. 
Matthews, Gareth B. The Philosophy of Childhood. Cambridge: Harvard UP, 1994. Print.

Maynes, Mary Jo. "Age as Category of Historical Analysis: History, Agency, and Narratives of Childhood." Journal of the History of Childhood and Youth 1.1 (Winter 2008): 114-124. Print.

Nikolajeva, Maria. Power, Voice, and Subjectivity in Literature for Young Readers. New York: Routledge, 2010. Print.

Nodelman, Perry. The Hidden Adult: Defining Children's Literature. Baltimore: Johns Hopkins UP, 2008. Print.

---. “The Other: Orientalism, Colonialism, and Children's Literature." Children's Literature Association Quarterly 17.1 (1992): 29-35. Print.

Oswell, David. The Agency of Children: From Family to Global Human Rights. New York: Cambridge UP, 2013. Print.

Prout, Alan. The Future of Childhood. New York: Routledge, 2005. Print.

Redcay, Anna. “'The Long-Defended Gate': Juvenilia, the Real Child, and the Aesthetics of Innocence, 1858-1934.” Diss. U of Pittsburgh, 2012. Print.

---. Rev. of Dependent States: The Child's Part in Nineteenth-Century American Culture, by Karen Sánchez-Eppler. Critical Quarterly 51.1 (2009): 139-46. Print.

Rorty, Richard. Philosophy and the Mirror of Nature. Princeton: Princeton UP, 1980. Print. Rose, Jacqueline. The Case of Peter Pan, or the Impossibility of Children's Fiction. Rev. ed. Philadelphia: U of Pennsylvania P, 1993. Print.

Rosenthal, Robert, and Lenore Jacobson. Pygmalion in the Classroom: Teacher Expectation and Pupils' Intellectual Development. New York: Holt, 1968. Print. 
Ryan, Kevin William. "The New Wave of Childhood Studies: Breaking the Grip of Bio-social Dualism?" Childhood 19.4 (2011): 439-52. Print.

Sánchez-Eppler, Karen. Dependent States: The Child's Part in Nineteenth-Century American Culture. Chicago: U of Chicago P, 2005. Print.

Schapiro, Tamar. “What Is a Child?” Ethics 109.4 (1999): 715-38. Print.

Sedgwick, Eve Kosofsky. Epistemology of the Closet. Rev. ed. Berkeley: U of California P, 2008. Print.

Thorne, Barrie. "Crafting the Interdisciplinary Field of Childhood Studies." Childhood 14.2 (2007): 147-52. Print.

Warner, Marina. “Little Angels, Little Monsters: Keeping Childhood Innocent.” Six Myths of Our Time: Little Angels, Little Monsters, Beautiful Beasts, and More. New York: Vintage, 1994. 43-62. Print.

Marah Gubar, Associate Professor of Literature at MIT, is the author of Artful Dodgers: Reconceiving the Golden Age of Children's Literature (Oxford University Press, 2009). She is working on a second book entitled How to Think about Children: Childhood Studies in the Academy and Beyond. It attempts to generate a philosophical framework for thinking about what it means to be a child that could function as a shared language, enabling researchers across the arts, the sciences, and the humanities to communicate their key insights about children and childhood not only with each other but also with people outside of academia. 